behavior was observed in this study, which indicates that the likelihood of encountering a very narrowband of vitamin $D$ values for patients with high disease activity is very high, and thus, the forecast capability of vitamin D values for patients with increasingly active disease is quite good. Future research will aim at strengthening the statistical parameters of relevance, identifying and characterizing the more specific behaviours of this global pattern.

Disclosure of Interest: None declared

DOI: 10.1136/annrheumdis-2017-eular.4062

\section{AB0301 CARDIOVASCULAR RISK AND END ORGAN DAMAGE IN AN ITALIAN GROUP OF PATIENTS WITH RHEUMATOID ARTHRITIS}

C.A. Valena ${ }^{1}$, S. Barbarossa ${ }^{1}$, G. Erba ${ }^{1}$, R. Facchetti ${ }^{2}$, A. Maloberti ${ }^{1}$, P. Villa ${ }^{1}$, I. Boggioni ${ }^{1}$, M. Riva ${ }^{1}$, G. Grassi ${ }^{1}$, M.R. Pozzi ${ }^{1} .{ }^{1}$ Clinica Medica Università Milano Bicocca; ${ }^{2}$ Dipartimento di Medicina Clinica e Prevenzione, Università Milano Bicocca, Monza, Italy

Background: The elevated cardiovascular burden of rheumatoid arthritis is well known and the recent update of EULAR recommendations for cardiovascular disease management (1) establish as overarching principle that the rheumatologist is responsible for CVD risk management in patients with RA. They highlight the need of optimal disease activity control, regular CVD risk assessment, lifestyle counseling, appropriate prescription of NSAIDS, corticosteroids, antihypertensives and statins. Screening for asymptomatic atherosclerotic plaques by use of carotid ultrasound is also suggested: the presence of carotid plaques is associated with poor CVD-free survival and is strongly linked to future acute coronary syndrome in RA patients.

Objectives: We performed an overall cardiovascular assessment to evaluate the presence of end-organ damage in a group of RA patients.

Methods: We carried out non-invasive 24 hours ambulatory blood pressure monitoring, echocardiography, carotid doppler ultrasound and pulse wave velocity (PWV) in a group of RA patients to optimize non-DMARDs therapy and to evaluate end organ damage.

Results: 55 RA patients, $76.4 \%$ female, mean age $62.8 \pm 9$ yrs were examined. The median disease duration was 12 yrs. $84 \%$ were RF +, 80\% ACPA + and $51 \%$ had erosions. Mean DAS 28 CRP was $2.82 \pm 1.23$ and HAQ 0.54 \pm 0.6 . All pts were treated with cDMARDs and/or bDMARDs (54\%) and Pd mean dosage was $\leq 5 \mathrm{mg} /$ day. Only 3 patients had previous CV event. $49 \%$ were hypertensive, $25 \%$ had high cholesterol, $13 \%$ diabetes and $16 \%$ were smokers: median BMI was 25 . MAP monitoring revealed that $43 / 55(78 \%)$ pts were hypertensive: 13 of them had unknown or not/under treated hypertension: $63 \%$ had dipper profile and only $12 \%$ were reverse dipper. We did not find increased left ventricular mass and wall thickness, but left ventricular diastolic dysfunction grade I-II was found in $26 / 55$ pts, not related to hypertension nor to RA activity. The IMT median value was 655 $\mathrm{mm}$; only in 3 pts was $>900 \mathrm{~mm}$ : no relation with disease activity was found. In 11 pts carotid plaques were present and related with age, BMI and ambulatory mean pressure values, but not with RA activity or duration. In one patient the plaque required carotid endarterectomy. The PWV median value was $>10 \mathrm{~m} / \mathrm{s}$ in 16 pts, all hypertensive.

Conclusions: The accurate evaluation of cardiovascular involvement of this small group of RA patients shows that hypertension is frequent and often not appropriately treated and seems to be the main cause of the increased PWV. Low grade LV diastolic dysfunction was found in half of patients, with no relation with hypertension or RA features, except for CCP presence, but the small numbers do not allow any speculation. Carotid artery involvement was present in $20 \%$ of pts, but only in 1 was clinically significant. Once again no relation with RA features was found: the small number of patients, the low disease activity and the tight and overall clinical control could be partial explanations. The clinical tight control of patients with RA is an unique opportunity to fulfill EULAR reccomendations. References:

[1] Agca R, et al. Ann Rheum Dis 2016

Disclosure of Interest: None declared

DOI: 10.1136/annrheumdis-2017-eular.4127

\section{AB0302 WORKABILITY IN PATIENTS WITH SEROPOSITIVE RHEUMATOID ARTHRITIS}

C. Berner ${ }^{1}$, T. Lamprecht ${ }^{2}$, K.H. Fenzl ${ }^{2}$, L. Erlacher ${ }^{1}$, T.E. Dorner ${ }^{3} .{ }^{1}$ 2nd Medical Division, Rheumatology, Kaiser Franz Josef Hospital, SMZ-Süd; ${ }^{2}$ Karl Landsteiner Society, Institute for Autoimmune IIInesses and Rheumatology; ${ }^{3}$ Institute of Social Medicine, Centre for Public Health, Medical University of Vienna, Vienna, Austria

Background: Rheumatoid arthritis (RA) and other rheumatic conditions can lead to work disability, and temporary or permanent exit from the labour market. The indirect costs related to work disability, are higher than direct treatment costs, and pose an economic burden on patients and society. Workability in RA is influenced by many factors, including symptoms, such as pain, swelling and stiffness, muscle strength, or physical or mental exhaustion, which are components of the frailty syndrome.

Objectives: This study aimed to determine the association of workability with disease activity, pain, functional disability and frailty in patients with seropositive rheumatoid arthritis.
Methods: We conducted a monocentric cross-sectional study at a rheumatologic outpatient clinic and day hospital including 100 seropositive RA patients (according to 2010 EULAR classification) in the working age ( $<65$ years). Workability was assessed with the self-administered Work Ability Index questionnaire. For disease activity, we used the Clinical Disease Activity Index (CDAI), a Visual analogue scale for pain assessment, for functional disability the self-administered Health Assessment Questionnaire Disability Index (HAQ-DI) and for the degree of frailty the SHARE Frailty Instrument (SHARE-FI). After testing for normal distribution, bivariate correlations between workability and associated variables were calculated using Spearman's correlation coefficients.

Results: Of 100 patients for 58 the workability index could be assessed. The remaining 42 were either unemployed, on disability pension, or employed but currently not working. These 58 patients, 37 women and 21 men, had an average age of 64.8 years ( $\min -\mathrm{max}=22-59, \mathrm{SD}=9.3$ ) and an average disease duration of 93.9 months (min-max $=3-360, S D=86.7$ ). 8 patients reported excellent workability, 27 good workability, 16 moderate workability and 7 poor workability. The workability was weakly correlated with age $\left(r_{\mathrm{s}}=-0.37, \mathrm{p}<0.004\right)$, and moderately correlated with pain intensity $\left(r_{\mathrm{s}}=0.42, \mathrm{p}<0.001\right)$, disease activity $\left(r_{\mathrm{s}}=0.40, \mathrm{p}<0.002\right)$, functional disability $\left(r_{\mathrm{s}}=0.64, \mathrm{p}<0.000\right)$ and frailty $\left(r_{\mathrm{s}}=0.623\right.$, $\mathrm{p}<0.000$ ).

Conclusions: A considerable portion of employed RA patients reported poor or moderate workability, which is significantly associated with disease activity but also with the other parameters assessed. An adequate therapy may therefore not only improve well-being and state of health in RA patients but also provide socioeconomically advantage by maintaining patients' workability.

Disclosure of Interest: None declared

DOI: 10.1136/annrheumdis-2017-eular.3567

\section{AB0303 DOES COMORBIDITY ADVERSELY IMPACT ON TREATMENT RESPONSE IN PATIENTS WITH RHEUMATOID ARTHRITIS}

C.D. Hughes, N. Gullick. Rheumatology, King's College Hospital, London, United Kingdom

Background: The burden of comorbid illness in Rheumatoid Arthritis is high. Whilst there can be coincidental existence of comorbidity, it can be attributed to the disease process itself or therapeutic agents. Recent EULAR guidelines recommend reporting, screening and prevention of six common co-morbidities (cardiovascular, malignancy, infections, gastrointestinal, osteoporosis, depression). Limited research is available evaluating the impact of comorbidity on disease response following biologic treatment.

Objectives: To analyse retrospective data from the King's College Hospital $(\mathrm{KCH})$ Virtual Biologic Clinic (VBC) to assess the impact of comorbidity on disease response following treatment with biologics.

Methods: Retrospective patient note review data was collected for patients referred to the VBC from May 2013 to July 2016. The following data was recorded: age, sex, disease duration, smoking status, BMI, presence or absence of Anti CCP antibody +/-Rheumatoid factor and the six specified comorbidities. Disease Activity Score in 28 joints (DAS28) at time of referral for biologic and within 6 months of commencing treatment was also recorded in order to calculate treatment response.

The impact of comorbidity and disease variables on 6 month EULAR response were analysed using logistic regression (SPSS version 23).

Results: The database contained 150 patients. 18 patients were excluded due to no follow-up DAS28, leaving 132 for analysis. Mean age and disease duration were 58 years and 10.45 years respectively. Comorbidity was present in $70 \%$ of patients. $70 \%$ of patients achieved a EULAR moderate response (improvement of $>1.2$ of DAS28) and $36 \%$ of this group achieved EULAR good response (DAS28<3.2). The most prevalent comorbidities were infection, cardiovascular disease and depression.

Logistic regression analysis was run analysing EULAR moderate response against presence of comorbidity and dataset variables (age, gender, serostatus, baseline DAS, HAQ and polypharmacy). The resulting model was not statistically significant $(p=0.975)$.

Logistic regression analysis looking at EULAR good response against presence of comorbidity was also not statistically significiant $(p=0.149)$. Analysis looking at EULAR good response against three variables (HAQ, baseline DAS and serostatus) was found to be statistically significant $(p<0.001)$

\begin{tabular}{|c|c|c|c|c|}
\hline Characteristics & $\begin{array}{c}\text { All } \\
\mathrm{N}=132\end{array}$ & $\begin{array}{c}\text { No EULAR } \\
\text { moderate response } \\
\mathrm{N}=40\end{array}$ & $\begin{array}{c}\text { EULAR } \\
\text { moderate response } \\
\mathrm{N}=92\end{array}$ & $\begin{array}{c}\text { EULAR } \\
\text { good response } \\
N=34\end{array}$ \\
\hline Age years (SD) & $58(13)$ & $56(10)$ & $59(14)$ & $57(11)$ \\
\hline Gender (\%F) & $79 \%$ & $72.5 \%$ & $81.5 \%$ & $76 \%$ \\
\hline Positive serostatus & $77 \%$ & $65 \%$ & $82 \%$ & $74 \%$ \\
\hline $\begin{array}{l}\text { RA Disease duration } \\
\text { (years) (SD) }\end{array}$ & $10.45(10.81)$ & $10.70(11.47)$ & $10.34(10.52)$ & $10.54(10.74)$ \\
\hline Prior biologic use & $55 \%$ & $60 \%$ & $52.2 \%$ & $32 \%$ \\
\hline Comorbidity & $70 \%$ & $80 \%$ & $82 \%$ & $62 \%$ \\
\hline Baseline DAS28 (SD) & $6.27(0.93)$ & $6.27(0.93)$ & $6.28(0.93)$ & $6.26(0.93)$ \\
\hline $\begin{array}{l}\text { Mean DAS improvement } \\
\text { (SD) }\end{array}$ & $1.97(1.57)$ & $1.97(1.57)$ & $1.99(1.58)$ & $1.95(1.58)$ \\
\hline
\end{tabular}

Conclusions: Comorbidities were present in the majority of patients assessed 